Tersedia Online: http://journal.unj.ac.id/unj/index.php/ipensil

\title{
PENGEMBANGAN MULTIMEDIA INTERAKTIF PADA MATA KULIAH MANAJEMEN KONSTRUKSI DI S1 PENDIDIKAN TEKNIK BANGUNAN UNIVERSITAS NEGERI JAKARTA
}

\author{
$\mathrm{R} r$ Indra Tanie Kusuma Negara ${ }^{1}$, Tuti Iriani ${ }^{2}$ Lenggogeni ${ }^{3}$ \\ 1,2,3 Universitas Negeri Jakarta

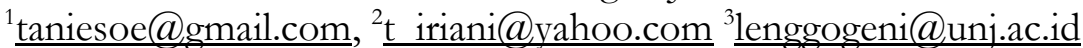

$\begin{array}{ll}\text { Diterima } & : \text { 28 Agustus } 2019 \\ \text { Direvisi } & : \text { 17 September } 2019 \\ \text { Diterbitkan } & : \text { 21 September 2019 } \\ \text { DOI } & : 10.21009 / \text { jpensil.v8i2.11966 }\end{array}$

Abstract

This study is aimed to develop multimedia interactive for Construction Management Course to facilitate student's learning and also assist the lecturer. Methodolgy used for this research is Research and Development $(\mathrm{R} n \mathrm{D})$. Multimedia interactive that is developed using Tutorial Model purposed to be a complement of student's learning. This research is done with using Lee and Owen's (2004) Development Modet. Collecting data technique for this study is using questionnaire.

The result of this Reasearch and Development $(\mathrm{R} n \mathrm{D})$ is ten multimedia interactive. The multimedia interactive is stated "very worthy" by media experts with score 90,68\% and also stated "very worthy" by material experts with score 90,68\%. The statement is srengthened by student's asessement that states if multimedia interactive is "very worthy" with score $87,36 \%$ The percentage showed that multimedia interactive is ready to be implemented for Construction Management Course.

Keywords: Multimedia Interactive, Construction Management, Lee and Owen.

\section{Pendahuluan}

Revolusi Industri 4.0 merupakan perkembangan besar keempat yang terjadi di bidang industri. Setiap revolusi industri melahirkan perubahan besar signifikan bagi kehidupan manusia. Revolusi industri 4.0 adalah kemajuan dibidang industri yang mengaitkan teknologi digital ke segala aspek. Hal ini menyebabkan revolusi industri menuntut kesiapan masyarakat terhadap peran serta teknologi digital di dalam segala aspek. Prasetyo \& Sutopo (2018) berpendapat bahwa digitalisasi dari revolusi industri memberikan tantangan bagi akademisi dan praktisi dalam beberapa aspek, yaitu pengetahuan, teknologi, sosial, ekonomi dan politik.

Revolusi industri 4.0 disebut juga Era Disrupsi yang berarti sebuah inovasi. Inovasi tersebut juga memberikan perubahan dibidang pendidikan. Hal ini terlihat pada ciri-ciri pembelajaran di Era Disrupsi, menurut Wibawa (2018) adalah sebagai berikut: self-directed (peserta didik merasa butuh), multi-sources (menggunakan banyak sumber), life-long learning (pembelajaran seumur hidup), self-motivated (motivasi peserta didik kuat), attitude (memiliki sikap tanggap terhadap perubahan), adaptive (mampu menyesuaikan diri), growth mindset (memiliki pemikiran yang terus berkembang), serta ICT base (pembelajaran menggunakan teknologi informasi) (Risdianto, 2019).

Poin terakhir pada ciri pembelajaran 'Era Disrupsi' adalah penggunaan teknologi informasi dalam proses pembelajaran. Teknologi informasi dapat dimaksimalkan pada media pembelajaran. Media pembelajaran adalah alat yang mempermudah proses penyampaian 
informasi yang dilakukan oleh pendidik dan menjadi alat bantu peserta didik dalam mengikuti proses pembelajaran. $\mathrm{Hal}$ tersebut berarti bahwa media yang digunakan harus memenuhi standar untuk dapat digunakan pendidik maupun peserta didik.

Multimedia merupakan media yang didalamnya terdapat dua unsur atau lebih media yang berisikan teks, gambar, grafik, audio dan video. Diungkapkan oleh Shea (1990) bahwa daya tangkap yang dimiliki peserta didik, $10 \%$ dari apa yang dibaca, $20 \%$ dari apa yang didengar, $30 \%$ dari apa yang dilihat, $50 \%$ dari apa yang dilihat dan didengar, $70 \%$ dari apa yang dikatakan, 90 $\%$ dari apa yang peserta didik lakukan, dalam Fakhriyanur (2016). Multimedia dikategorikan menjadi dua, yaitu multimedia linear dan multimedia interaktif. Multimedia linear adalah gabungan beberapa media yang tidak dilengkapi dengan alat pengontrol bagi penggunanya (Heriawati, Sudjarwo, \& Herpratiwi, 2014). Sedangkan multimedia interaktif adalah penggunaan beberapa media dimana peserta didik berperan aktif didalam proses pembelajaran demi tercapainya tujuan pembelajaran.

Hal yang menjadi kunci dalam multimedia interaktif adalah dimana media tersebut merangsang peserta didik untuk melakukan interaksi-interaksi yang telah diprogram dalam media pembelajaran. Peserta didik tidak hanya menyimak materi yang ditampilkan, tetapi juga berperan aktif di dalamnya (Kusantati dkk, 2014). Penggunaan banyak media mampu meningkatkan rangsangan daya tangkap peserta didik.

Pendidikan Teknik Bangunan merupakan program studi di Universitas Negeri Jakarta dengan kompetensi lulusan sebagai pendidik di bidang vokasi konstruksi bangunan. Selama perkuliahan mahasiswa dibekali dengan ilmu-ilmu konstruksi, salah satunya melalui mata kuliah Manajemen Konstruksi. Mata kuliah manajemen konstruksi mempelajari tentang ilmu dasar manajemen dalam proyek konstruksi. Tujuan dari mata kuliah
Manajemen Konstruksi adalah agar mahasiswa dapat membuat perencanaan jadwal dan pengendalian biaya pada proyek konstruksi. Outcome dari mata kuliah manajemen konstruksi adalah mahasiswa mampu merencanakan (create). Merencanakan atau membuat merupakan tingkat tertinggi (C6) pada tingkatan kognitif Taksonomi Anderson dan Khratwol (2001).

Media pembelajaran yang digunakan pada mata kuliah Manajemen Konstruksi di S1 Pendidikan Teknik Bangunan Universitas Negeri Jakarta adalah slide presentasi visual 2 dimensi. Media yang digunakan berisi teks, grafik dan gambar. Media yang digunakan tersebut menurut Seels dan Glasgow (1990) merupakan kategori media pembelajaran tradisional. Daya tangkap mahasiswa yang didapat dengan menggunakan media slide presentasi maksimal 50\%. Presentase ini merupakan angka yang minim untuk menunjang tujuan pembelajar Mata Kuliah Manajemen Konstruksi. Mengingat outcome mata kuliah Manajemen Konstruksi yang berupa perencanaan, dibutuhkan media yang mampu membantu mahasiswa memahami dan merencanakan hal-hal terkait proyek konstruksi.

Mata kuliah Manajemen Konstruksi terdiri dari sembilan topik pembelajaran. 44,44\% topik memiliki tujuan menciptakan (C6), 22,22\% bertujuan menerapkan (C3), $22,22 \%$ bertujuan memahami (C2) dan $11,1 \%$ bertujuan mengevaluasi (C5). Secara keseluruhan, mata kuliah Manajemen Konstruksi memiliki tujuan pembelajaran dengan level yang tinggi yaitu menciptakan (C6). Selain itu, pada mata kuliah Manajemen Konstruksi terdapat topik pembelajaran yang berkesinambungan. Jadi, mahasiswa perlu benar-benar memahami setiap topik. Topik yang berkesinambungan yaitu 'Activity on Arrow Method' dengan 'Critical Path Method' serta 'Barchart dan Kurva S' dengan 'Kebutuhan dan Penjadwalan Tenaga Kerja serta Material'.

Media yang digunakan saat ini tidak sesuai dengan ciri pembelajaran 'Era 
Disrupsi' yang menonjolkan penggunaan teknologi dalam proses pembelajarannya. Sebanyak $100 \%$ mahasiswa setuju bahwa media pembelajaran Mata Kuliah Manajemen Konstruksi perlu dikembangkan. Hasil final dari analisa kebutuhan menunjukan bahwa 83,6\% mahasiswa setuju untuk mengembangkan multimedia interaktif sebagai media pembelajaran Mata Kuliah Manajemen Konstruksi.

Selain itu, presentase kelulusan mata kuliah Manajemen Konstruksi selama tiga tahun terakhir mengalami penurunan. Presentase kelulusan mahasiswa pada Mata Kuliah Manajemen Konstruksi pada semester 104, 106, dan 108 berturut-turut adalah $86,3 \%, 85,7 \%$ dan $85 \%$. Penurunan jumlah mahasiswa yang lulus mata kuliah Manajemen Konstruksi menjadi faktor yang perlu dipertimbangkan dalam mengembangkan media pembelajaran agar meningkatkan minat serta daya serap mahasiswa terhadap suatu mata kuliah (Al Masjid \& Arief, 2016).

Berdasarkan rumusan masalah diatas, maka penulis akan melakukan penelitian dengan judul "Pengembangan Multimedia Interaktif pada Mata Kuliah Manajemen Konstruksi di S1 Pendidikan Teknik Bangunan Universitas Negeri Jakarta".

Berdasarkan rumusan masalah di atas, penelitian ini bertujuan untuk mengembangkan multimedia interaktif sebagai fasilitas pada Mata Kuliah Manajemen Konstruksi yang merepresentasikan kebutuhan-kebutuhan mahasiswa serta sebagai alat bantu ajar dikelas.

Manfaat dari penelitian ini adalah: 1)Motivasi belajar mahasiswa meningkat dikarenakan media pembelajaran baru; 2)Pemahaman mahasiswa terhadap materi pembelajaran Manajemen Konstruksi meningkat; 3)Membantu mahasiswa untuk mendapatkan media pembelajaran yang mudah digunakan, mudah dipahami, menarik dan kontekstual; 4)Memfasilitasi mahasiswa dengan media pembelajaran yang up-to-date.

\section{Metode Penelitian}

Metode penelitian yang digunakan pada penelitian ini adalah Reasearch and Development $(\mathrm{RnD})$ dengan menggunakan Model Pengembangan Lee and Owens (2004). Teknik pengumpulan data dilakukan dengan penyebarluasan angket kepada 2 orang ahli media, 2 orang ahli materi dan mahasiswa. Rangkaian tahap penelitian sesuai dengan pendapat yang dikemukakan (Haryono, 2015) berupa: 1) Melakukan analisa kebutuhan terhadap media pembelajaran pada mata kuliah Manajemen Konstruksi; 2) Membuat desain produk multimedia interaktif berdasarkan saransaran pada analisa kebutuhan; 3) Mengembangkan multimedia interaktif; 4) Melakukan uji validasi kepada 2 orang ahli media dan 2 orang ahli materi; 5) Mengevaluasi hasil uji validasi dan melakukan perbaikan.

\section{Hasil Penelitian dan Pembahasan}

Pengembangan multimedia interaktif ini dilakukan dengan mengikuti teori - teori yang terdapat pada multimedia interaktif. Pengembangan multimedia interaktif dilakukan dengan menggunakan model pengembangan Lee and Owen (2004). Tahap yang dilakukan sampai pada tahap terakhir yaitu evaluation. Rangkaian tahapan yang utuh dapat memberikan kepastian kelayakan produk. Hasil kelayakan menunjukan bahwa multimedia interaktif yang dikembangkan "sangat layak" menurut ahli media, dengan skor penilaian 90,68\%. Konten multimedia interaktif dinyatakan "sangat layak" oleh ahli materi dengan skor penilaian $81,64 \%$.

Tabel 1 Hasil Validasi Ahli Media

\section{No Aspek yang Presentase Ket.} dinilai

\begin{tabular}{llll}
\hline 1 & Visual & $87,14 \%$ & $\begin{array}{l}\text { Sangat } \\
\text { Layak }\end{array}$
\end{tabular}




\begin{tabular}{llcl}
2 & $\begin{array}{l}\text { Kebahasaan } \\
\text { \& } \\
\text { Komunikasi }\end{array}$ & $96,66 \%$ & $\begin{array}{l}\text { Sangat } \\
\text { Layak }\end{array}$ \\
\hline 3 & Keefektifan & $87,5 \%$ & $\begin{array}{l}\text { Sangat } \\
\text { Layak }\end{array}$ \\
\hline 4 & $\begin{array}{l}\text { Level } \\
\text { Interaktifitas }\end{array}$ & $91,42 \%$ & $\begin{array}{l}\text { Sangat } \\
\text { Layak }\end{array}$ \\
\hline Jumlah & $90,68 \%$ & $\begin{array}{l}\text { Sangat } \\
\text { Layak }\end{array}$ \\
\hline
\end{tabular}

Tabel hasil validasi media diatas menunjukan bahwa multimedia interaktif dikembangkan sesuai dengan aturan-aturan yang harus terkandung dalam media pembelajaran. Terutama pada aspek kebahasaan dan komunikasi, aspek tersebut merupakan poin penting dari media pembelajaran menurut (Lisiswanti, Saputra, \& Windarti, 2015). Level interaktifitas juga disajikan dengan baik sampai pada pemberian feedback yang merupakan salah satu ciri utama dari multimedia interaktif meurut (Soenarto, 2015). Dari segi visual dan juga keefektifan, multimedia interaktif dinilai sangat layak.

\section{Tabel 2 Hasil Validasi Ahli Materi}

\begin{tabular}{cccc}
\hline No & Judul & $\%$ & Ket. \\
& Materi & Total &
\end{tabular}

\begin{tabular}{llcl}
\hline 1. & $\begin{array}{l}\text { Dasar-Dasar } \\
\text { Manajemen }\end{array}$ & $\begin{array}{c}73,57 \\
\%\end{array}$ & Layak \\
\hline 2. & $\begin{array}{l}\text { Organisasi } \\
\text { Proyek } \\
\text { Konstruksi }\end{array}$ & $\begin{array}{c}72,14 \\
\%\end{array}$ & Layak \\
& & \\
\hline 3. & $\begin{array}{l}\text { Activity on } \\
\text { Arrow }\end{array}$ & $80 \%$ & Layak \\
& & \\
\hline 4. & Metode & 81,42 & Sangat Layak \\
& Jalur Kritis & $\%$ & \\
\hline 5. & Barchart & 86,42 & Sangat Layak \\
& & $\%$ & \\
& &
\end{tabular}

\section{Kurva S 86,42 Sangat Layak \\ $\%$}

\begin{tabular}{llcc}
\hline 7. & $\begin{array}{l}\text { Kebutuhan } \\
\text { \& } \\
\text { Penjadwalan } \\
\text { Tenaga } \\
\text { Kerja \& } \\
\text { Material }\end{array}$ & & \\
& & \\
\hline 8. & Cashflow & $85 \%, 71$ & Sangat Layak \\
& & $\%$ & \\
\hline 9. & $\begin{array}{l}\text { Precedence } \\
\text { Diagramming } \\
\text { Method }\end{array}$ & $85 \%$ & Sangat Layak \\
& & \\
\hline 10. & Earned Value & 85,71 & Sangat Layak \\
& & $\%$ & \\
\hline Jumlah & 81,64 & Sangat Layak \\
& & $\%$ & \\
\hline
\end{tabular}

Tabel hasil validasi ahli materi diatas menunjukan bahwa secara keseluruhan konten materi pada multimedia interaktif sudah sangat baik. Namun ada beberapa materi yang perlu ditambahkan, khususnya pada materi Dasar-Dasar Manajemen dan Organsasi Proyek Konstruksi. Materi yang perlu ditambahkan berupa analisis SWOT, diagram matrix, garis koordinasi, contoh koordinasi serta garis perintah. Konten materi perlu diperbaiki sesuai dengan saran dari validator karena menurut (Nopriyanti \& Sudira, 2015) materi yang jelas dan konsisten merupakan ciri multimedia interaktif.

Multimedia interaktif yang dikembangkan merupakan media berbasis teknologi karena memanfaatkan penggunaan teknologi dalam pembuatan serta pengoperasiannya. Multimedia interaktif yang dikembangkan memuat materi yang diikuti dengan latihan-latihan soal, selaras dengan strategi pembelajaran yang digunakan. Multimedia interaktif yang berisi materi dan latihan soal juga sesuai dengan model multimedia interaktif yang dipilih, yaitu model tutorial. Menurut pendapat (Surjono, 2017) disebutkan bahwa 
model tutorial pada multimedia interaktif memuat rangkaian materi yang tersusun sistematis dan dilanjutkan dengan latihan soal. Latihan soal yang disajikan juga diungkapkan dalam analisa kebutuhan sebagai kebutuhan dasar bagi mahasiswa. Multimedia interaktif yang dikembangkan akan digunakan sebagai komplemen dalam pembelajaran, sesuai dengan porsi media pembelajaran di dalam strategi pembelajaran. Media sebagai komplemen berarti multimedia interaktif diprogramkan untuk melengkapi pembelajaran yang dilakukan oleh pendidik di kelas (Sujoko, 2013).

Sebelum Pengembangan, materi berjumlah 9, media yang digunakan berupa teks, grafik dan gambar serta tidak ada interaktifitas. Sesudah dilakukan pengembangan materi berjumlah 10 . Perubahan jumlah materi karena materi Barchart dan Kurva S dipisah menjadi dua materi yang berbeda. Hal tersebut dikarenakan fungsi materi yang berbeda di dalam proyek konstruksi. Barchart digunakan sebagai metode penjadwalan sedangkan kurva S sebagai kontrol pelaksanaan proyek. Media yang digunakan berupa teks, grafik, gambar serta video pada beberapa materi. Serta interaktifitas yang dikembangkan berupa: Navigasi untuk video, navigasi halaman, kontrol menu/link, kontrol animasi, Hypermap serta pemberian respon atau feedback.

Pada saat validasi, ada beberapa saran yang diberikan oleh ahli media terkait produk multimedia interaktif yang dikembangkan, yaitu: 1)Ubah voiceover untuk video dengan suara yang lebih menarik; 2)Struktur link dan navigasi dipermudah; 3)Perbaiki petunjuk penggunaan dengan menggunakan roll-over; 4)Konsistensi pada tampilan menu; 5)Setiap bagian media harus dibuat kembali ke beranda; 6)Tambahkan recently back; 7)Tambahkan slide untuk menuju pembahasan soal yang ada dalam latihan soal; 8)Tambahkan petunjuk pengerjaan latihan soal; 9)Tambahkan penguatan pada umpan balik program latihan soal; 10)Sebaiknya video dibuat dalam bentuk byperlink supaya tidak memakai banyak memori; 11)Akan lebih baik jika dikembangkan dengan software multimedia

Tabel 3 Perbaikan yang Dilakukan

\begin{tabular}{|c|c|c|c|}
\hline No & \multicolumn{2}{|c|}{ Sebelum Revisi } & Sesudah Revisi \\
\hline 1 & $\begin{array}{l}\text { Ubah } \\
\text { untuk } \\
\text { dengan } \\
\text { yang } \\
\text { menarik }\end{array}$ & $\begin{array}{r}\text { voiceover } \\
\text { video } \\
\text { suara } \\
\text { lebih }\end{array}$ & $\begin{array}{l}\text { Mengganti video } \\
\text { dengan voiceover } \\
\text { yang menarik }\end{array}$ \\
\hline 2 & \multicolumn{2}{|c|}{$\begin{array}{l}\text { Struktur link dan } \\
\text { navigasi } \\
\text { dipermudah }\end{array}$} & $\begin{array}{l}\text { Mempermudah } \\
\text { struktur link dan } \\
\text { navigasi }\end{array}$ \\
\hline 3 & \multicolumn{2}{|c|}{$\begin{array}{l}\text { Perbaiki } \\
\text { petunjuk } \\
\text { penggunaan } \\
\text { dengan } \\
\text { menggunakan } \\
\text { roll-over }\end{array}$} & $\begin{array}{l}\text { Memperbaiki } \\
\text { petunjuk } \\
\text { penggunaan }\end{array}$ \\
\hline
\end{tabular}

4 Konsistensi pada Memilih desain tampilan menu yang konsisten

\begin{tabular}{|c|c|c|}
\hline 5 & $\begin{array}{lr}\text { Setiap } & \text { bagian } \\
\text { media } & \text { harus } \\
\text { dibuat kembali } & \text { ke beranda }\end{array}$ & $\begin{array}{ll}\text { Menghapus } & \text { icon } \\
\text { next pada setiap } \\
\text { akhir bagian } \\
\text { media } \\
\text { pembelajaran }\end{array}$ \\
\hline 6 & $\begin{array}{l}\text { Tambahkan } \\
\text { recently back. }\end{array}$ & $\begin{array}{l}\text { Menambahkan } \\
\text { recently back }\end{array}$ \\
\hline 7 & $\begin{array}{l}\text { Tambahkan slide } \\
\text { untuk menuju } \\
\text { pembahasan soal } \\
\text { yang ada dalam } \\
\text { latihan soal }\end{array}$ & $\begin{array}{l}\text { Membuat slide } \\
\text { byperlink menuju } \\
\text { pembahasan soal }\end{array}$ \\
\hline 8 & $\begin{array}{l}\text { Tambahkan } \\
\text { petunjuk } \\
\text { pengerjaan } \\
\text { latihan soal }\end{array}$ & $\begin{array}{l}\text { Menambahkan } \\
\text { petunjuk } \\
\text { pengerjaan soal }\end{array}$ \\
\hline 9 & $\begin{array}{l}\text { Tambahkan } \\
\text { penguatan pada }\end{array}$ & $\begin{array}{l}\text { Menambahkan } \\
\text { respon penguatan }\end{array}$ \\
\hline
\end{tabular}




\begin{tabular}{|c|c|c|}
\hline & $\begin{array}{l}\text { umpan balik } \\
\text { program latihan } \\
\text { soal }\end{array}$ & $\begin{array}{l}\text { sebagai } \\
\text { balik } \\
\text { program } \\
\text { soal }\end{array}$ \\
\hline 10 & $\begin{array}{lr}\text { Sebaiknya video } \\
\text { dibuat dalam } \\
\text { bentuk byperlink } \\
\text { supaya tidak } \\
\text { memakai banyak } \\
\text { memori }\end{array}$ & $\begin{array}{l}\text { Menginput video } \\
\text { dalam bentuk link }\end{array}$ \\
\hline 11 & $\begin{array}{l}\text { Akan lebih baik } \\
\text { jika } \\
\text { dikembangkan } \\
\text { dengan software } \\
\text { multimedia }\end{array}$ & $\begin{array}{l}\text { Menggunakan } \\
\text { software Adobe } \\
\text { Captivate }\end{array}$ \\
\hline
\end{tabular}

Tabel di atas menunjukan perbedaan multimedia interaktif sebelum dan sesudah dilakukan perbaikan. Penulis melakukan perbaikan sesuai dengan saran yang diberikan oleh validator. Sebelumnya software yang digunakan berupa Microsoft PowerPoint, kemudian digunakan software tambahan berupa Adobe Captivate untuk menjalankan fungsi-fungsi interaktifnya. Sedangkan Microsoft PowerPoint digunakan sebagai wadah awal untuk membuat desain serta mengolah konten materi yang akan disajikan. Perpaduan antara kedua software yang digunakan mempermudah penulis dalam mengembangkan multimedia interaktif.

Pengembangan multimedia interaktif juga dilakukan dengan arahan dari dosen pembimbing media dan dosen pembimbing materi. Pada penelitian pengembangan multimedia interaktif ini penulis mendapatkan dukungan berupa 1) Arahan dosen pembimbing selama pengembangan multimedia interaktif dilakukan; 2) Tersedianya RPS yang menjadi acuan pengembangan materi; 3) Tersedianya media lama untuk dijadikan bahan pertimbangan dalam pengembangan multimedia interaktif; 4) Ketersediaan bahan ajar yang menjadi sumber pengembangan materi.
Ketersediaan bahan-bahan yang dibutuhkan membantu penulis dalam mengembangkan produk terutama pada tahap Analys. RPS, bahan ajar serta media yang lama menjadi pertimbangan penulis untuk dapat lanjut ke tahap selanjutnya, yaitu tahap Design. Dengan mengacu kepada RPS, bahan ajar, media pembelajaran yang selama ini digunakan serta hasil analisa kebutuhan, penulis mengembangkan ide-ide untuk membuat design multimedia interaktif yang sesuai dengan kebutuhan mahasiswa.

Didalam pengembangan multimedia interaktif, penulis menemui beberapa kesulitan diantaranya: 1) Menemukan software yang sesuai untuk produk yang akan dikembangkan; 2) Menemukan video yang bersumber dari Youtube dengan kualitas dan isi materi yang relevan; 3) Sumbersumber materi lain diluar bahan ajar dosen.

Kesulitan di atas menjadi penghambat bagi penulis pada saat tahap Development. Dikarenakan kesulitan menemukan software dan keterbatasan waktu untuk belajar mengoperasikannya, struktur navigasi yang disajikan dinilai kurang maksimal menurut ahli media. Keterbatasan video yang bersumber dari youtube juga membuat multimedia interaktif dinilai kurang maksimal menurut ahli materi. Serta keterbatasan materi diluar bahan ajar dosen juga menjadi faktor yang dinilai kurang oleh ahli materi.

Multimedia interaktif ini memiliki beberapa kelebihan diantaranya: 1)Multimedia interaktif dapat digunakan dimana saja dan kapan saja; 2)Multimedia interaktif merepresentasikan kebutuhan mahasiswa yaitu memuat materi yang mudah dipahami (komunikatif) serta memuat contoh dan latihan soal perhitungan; 3)Multimedia interaktif tidak mengharuskan penggunanya memiliki suatu aplikasi khusus, karena yang dibutuhkan hanya aplikasi search engine seperti Google Chrome, Mozilla Firefox, Internet Explorer dan lain-lain.

Kemudahan penggunaan multimedia interaktif dalam hal penggunaan dan juga 
komunikasi telah memenuhi fungsi media sebagai alat bantu dalam pembelajaran. Media pembelajaran yang baik merupakan media yang membantu pengajar dalam mengkomunikasikan materi yang akan disampaikan.

Adapun kekurangan dari multimedia interaktif yang dikembangkan ini adalah 1) Konten video pada multimedia interaktif tidak dapat diputar jika tidak ada koneksi internet; 2) Multimedia interaktif tidak dapat berdiri sendiri yang berarti media tersebut tidak dapat dipisahkan dari supporter file nya; 3) Media pembelajaran multimedia interaktif hanya bisa dioperasikan menggunakan laptop.

Poin pertama pada kekurangan multimedia interaktif dapat diatasi dengan tersedianya wifi di gedung perkuliahan lingkungan Universitas Negeri Jakarta, sehingga mahasiswa dapat mengakses internet apabila masih dalam lingkungan Universitas Negeri Jakarta. Kekurangan multimedia interaktif poin kedua yaitu banyaknya file dalam folder multimedia interaktif karena file utama tidak dapat dipisahkan dengan supporter file-nya, kekurangan tersebut dapat diatasi dengan mengubah nama pada file utama multimedia interaktif menjadi "Materi $\mathrm{Ke}$ - Judul Materi”. Serta pada poin ketiga, penulis menjadikan saran untuk penelitian lanjutan agar multimedia interaktif dapat dioperasikan pada handphone.

\section{Simpulan}

Penelitian dan pengembangan multimedia interaktif telah dilakukan melalui serangkaian kegiatan dalam model pengembangan Lee and Owen (2004). Berdasarkan rangkaian kegiatan yang berupa analys, design, develop, implementation dan evaluation, dapat disimpulkan bahwa multimedia interaktif yang dikembangkan pada mata kuliah Manajemen Konstruksi sudah sangat sesuai dengan kebutuhan mahasiswa yang diungkapkan sebelumnya pada kegiatan analisa kebutuhan. Multimedia interaktif juga dinyatakan sangat layak untuk digunakan dari segi media, segi materi.

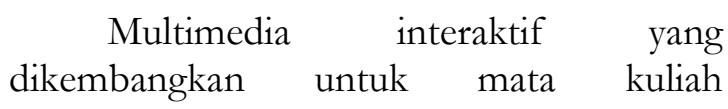
Manajemen Konstruksi dapat menjadi fasilitas bagi pembelajaran mahasiswa. Dikarenakan multimedia interaktif yang dikembangkan mengacu kepada kebutuhan dasar mahasiswa untuk memfasilitasi pembelajaran mahasiswa. Penggunaan multimedia interaktif pada mata kuliah Manajemen Konstruksi diduga dapat meningkatkan minat serta motivasi belajar mahasiswa, meningkatkan pemahaman mahasiswa serta kemauan 'belajar dimana saja dan kapan saja'.

Berdasarkan hasil penelitian dan pengembangan multimedia interaktif pada mata kuliah Manajemen Konstruksi di S1 Pendidikan Teknik Bangunan Universitas Negeri Jakarta, penulis dapat memberikan beberapa saran yaitu multimedia interaktif dapat digunakan sebagai media pembelajaran pada mata kuliah Manajemen Konstruksi, penelitian dapat dilanjutkan dengan menguji coba keefektifan produk pada skala kelompok yang lebih besar serta multimedia interaktif dapat dikembangkan lebih lanjut dengan memperkaya link interaktif yang dapat meningkatkan rasa ingin tahu mahasiswa. Multimedia interaktif juga dapat dikembangkan agar bisa diakses dengan menggunakan handphone sehingga penggunaannya akan lebih praktis.

\section{Daftar Pustaka}

Al Masjid, A., \& Arief, A. (2016). Pengguaan Multimedia Interaktif untuk Meningkatkan Kemampuan Membaca Aksara Jawa pada Siswa Kelas 5 SD Negeri Blimbing 4. Jurnal Pendidikan Ke-SD-An, 3, 48-54.

Fakhriyanur. (2016). Pengembangan Media Pembelajaran Interaktif teknik Animasi 2 Dimensi Berbasis Adobe Flash Untuk Siswa kelas XI Multimedia Di SMK Muhammadiyah 1 Yogyakarta. In Jurnal Pendidikan Teknik Elektronika (Vol. 5).

Pengembangan Multimedia Interaktif ... - 
Haryono, N. D. (2015). Pengembangan Multimedia Interaktif Sebagai Media Pembelajaran Ilmu Pengetahuan Sosial Materi Koperasi Bagi Siswa Kelas IV SD Negeri Tegalpanggung Yogyakarta. 3(2), 54-67.

Heriawati, N., Sudjarwo, \& Herpratiwi. (2014). Pengembangan Multimedia Interakif untuk Pembelajaran Management File Microsoft Word Siswa Kelas X SMA Di Kalianda. 115.

Kusantati, H., Marlina, \& Wiana, W. (2014). Evaluasi Multimedia Interaktif Berbasis Animasi Pada Pembelajaran Teknologi Desain Busana. Jurnal Invotec, X(1), 35-46.

Lisiswanti, R., Saputra, O., \& Windarti, I. (2015). Peranan Media dalam Pembelajaran 1,2,3. Jurnal Kesehatan, VI (Kesehatan), 102-105.

Nopriyanti, \& Sudira, P. (2015). Pengembangan Multimedia

Pembelajaran Interaktif Developing Interactive Learning Multimedia the Basic Competency in Installing Lighting and. Jurnal Pendidikan Vokasi Pengembangan, 5(1), 222-235.

Prasetyo, H. \& Sutopo, W. (2018). Industri 4.0: Telaah Klasifikasi Aspek dan Arah Perkembangan Riset. Jati Undip : Jurnal
Teknik Industri, 13(1), 17-26. https://doi.org/10.1470/jati.13.1.1726

Risdianto, E. (2019). Analisis Pendidikan Di Indonesia, 1-16. Diambil dari: https://www.academia.edu/38353914 /Analisis_Pendidikan_Indonesia_di_E ra_Revolusi_Industri_4.0.pdf. Diakses pada : 25 Mei 2019.

Soenarto, D. S. (2015). Pemanfaatan Teknologi Komunikasi dan Informasi untuk Mengembangkan Sumber Belajar Bidang Penyuluhan Pertanian. 1-17, Pusat Pembinaan dan Pengembangan Aktivitas Instruksional : Universitas Negeri Yogyakarta.

Sujoko. (2013). Pemanfaatan Teknologi Informasi dan Komunikasi sebagai Media Pembelajaran di SMP Negeri 1 Geger Madiun. Jp Jurnal Pendidikan. 1, 71-76.

Surjono, H. D. (2017). Multimedia Pembelajaran Interaktif Konsep dan Pengembangan. Yogyakarta. UNY Press. 